\title{
IIIJurnals BAHIANA
}

\section{The yearly cost of formatting and why Evidence decided to focus on science and not on a favorite typeface}

\author{
João de Deus Barreto Segundo', Luis Cláudio Correia² \\ ${ }^{1}$ Corresponding author. Federal University of Bahia, BAHIANA - School of Medicine and Public Health. Salvador, Bahia, Brazil. \\ ORCID: 0000-0002-4802-6045. jao.barreto@gmail.com \\ BAHIANA - School of Medicine and Public Health, Aliança Hospital. Salvador, Bahia, Brazil. ORCID: 0000-0002-6910-1366. luis.correia@bahiana.edu.br
}

What is more important to you? The birthday gift or the wrapping? We would say it is probably the gift. Unless you are a cat, which you are not. So, why it is that we as a community keep up with the exaggerated amount of formatting requirements some journals impose? According to a new survey just published at PLoS One, the cost of formatting papers amounts to a yearly week's worth of work'. And, to some, that is grant money, less time for teaching, at the laboratory or at the practice.

Due to its design, the study's sample was very likely comprised mostly of native English speakers from fields of research in the health sciences ${ }^{1}$, so that is why these results are so troublesome (and important) to us.

So, we would like to ask you the following: what would you do if you should have a free week every year? One could look for a new apartment, in a quieter neighborhood, pack up their things and move up. Or one could finally catch up with Stephen King's It: A Novel (which is a little over 1100 pages). Or enjoy some quality time with their kids. Or draft a new paper. Or conceive a new study design. And the list goes on and on. We should stop caring so much about the wrapping and start to focus on the science. Let the publishers focus on the formatting. The article processing charges and the publishing fees are for that, are they not? If the predictive value of biomedical research (and its inherent quality) is as low as expected ${ }^{2-4}$, then we are wasting precious time on the icing and little time on the recipe of the cake.

At the Evidence headquarters, we value our authors and their time. We expect our journal to to be a community (not just another biomedical journal). Communities take care of their members and value their time and contribution. In light of that, we have grouped our author guidelines by topics and restricted them to 12 simple requirements. Authors are instructed as to which typeface to submit their papers with, and which font size. We actually do that. But we truly do not care if you submit it in Comic Sans, as long as it is methodologically sound. No submission was ever desk rejected here because of the chosen typeface selected or spacing between lines and margins. We had to publish that item because authors would write to us asking if they had submitted the paper properly. So, to keep expectations clear, it is there and that is just that. It is a guideline and a map of sorts, not a roadblock.

Author contributions and competing interests disclosure forms are essentials of course. But we have decided we will only request those after 
the papers are reviewed, corrected and accepted for publication. We of course want to know if all authors listed on the submission really do qualify for the authorship of the paper. But that is not a necessity to the evaluation of the scientific merit of the paper in itself, is it?

Informed consent and ethical approval confirmation by the proper ethics committee and respect to copyrighted material are, of course, non-negotiable. Because these items are essential to establishing a relationship of trust between authors and editors, readers and journal. Those are requested upon submission because, above all, we have a deep respect and commitment to human life and scientific integrity. Everything else can be either requested upon acceptance or adjusted by our copy desk and art direction team.

We kindly suggest the other journals to follow suit. We need to focus more on the quality of the science that we publish.

\section{References}

1. LeBlanc AG, Barnes JD, Saunders TJ, Tremblay MS, Chaput JP. Scientific sinkhole: The pernicious price of formatting. PLoS One. 2019;14(9):e0223116. doi: 10.1371/journal.pone.0223116

2. Altman DG. The scandal of poor medical research. BMJ. 1994;308:283. doi: 10.1136/bmj.308.6924.283

3. Ioannidis JPA. Why Most Published Research Findings Are False. PLoS Med. 2005;2(8):e124. doi: 10.1371/journal.pmed.0020124

4. Ioannidis JPA. Why Most Clinical Research Is Not Useful. PLoS Med. 2016;13(6):e1002049. doi: 10.1371/journal.pmed.1002049 